\title{
NEGAÇÃO E ESVAZIAMENTO DO CAMPO: O QUE A ESCOLA TEM A VER COM ISSO?
}

\author{
Odimar J. Peripolli ${ }^{1}$ \\ https://orcid.org/0000-0002-0596-6213
}

Flávia Lorena Brito https://orcid.org/0000-0003-3431-8650

RESUMO: O presente trabalho tem por objetivo trazer para o debate questões que envolvem o campo, mais especificamente, o esvaziamento e envelhecimento da população (camponesa) e a escola. Sobretudo, nas últimas décadas, há um campo que se esvazia e envelhece. Por que isso vem ocorrendo? E a educação/ escola nesse processo? $\mathrm{O}$ texto traz um debate teórico com autores que discutem o tema na atualidade. A organização estrutural do texto procura demonstrar que o fenômeno estudado está diretamente relacionado a seu contexto, o que permite uma reflexão para além das imposições do capital para a educação do campo. As discussões, análises e conclusões mostram que a condição da reprodução da agricultura camponesa (mais afetada pelo fenômeno) é fato central no estabelecimento de uma relação específica entre a manutenção e estagnação dos espaços rurais.

PALAVRAS-CHAVE: campo, esvaziamento do campo, educação escolar.

\footnotetext{
${ }^{1}$ Doutor em Educação da Faculdade de Educação e Linguagem e do Programa de Pós-Graduação em Educação, Universidade do Estado de Mato Grosso (UNEMAT). Membro do Grupo de Pesquisa "Educação e Diversidade no Contexto da Amazônia Legal Matogorssense" (Unemat/CNPQ). Sinop/Mato Grosso/Brasil. ojperipolli@gmail.com

${ }^{2}$ Doutoranda em Educação (2019) pela Universidade Federal de Mato Grosso (PPGE/UFMT). Membro do GEPTE (Grupo de Estudos e Pesquisa sobre Trabalho e Educação) - UFMT. Mestre em Educação pela Universidade do Estado de Mato Grosso (UNEMAT), Programa de Pós-Graduação em Educação (PPGEdu/2015). Técnica em Assuntos Educacionais no IFMT - Campus Barra do Garças/Mato Grosso/Brasil. flaviaauiri@ yahoo.com.br
}

Rev. Fac. Educ. (Univ. do Estado de Mato Grosso), Vol. 31, Ano 17, № 1, p. 135-159, jan./jun., 2019 
ABSTRACT: The present work aims to bring to the debate issues that involve the field, more specifically, the emptying and aging of the population (peasant) and the school. Above all, in the last decades, there is a field that empties and ages. Why has this been happening? What about education / school in this process? The text brings a theoretical debate with authors who discuss the subject nowadays. The structural organization of the text tries to demonstrate that the studied phenomenon is directly related to its context, which allows a reflection beyond the impositions of the capital for the education of the field. Discussions, analyzes and conclusions show that the condition of the reproduction of family agriculture (more affected by the phenomenon) is central to the establishment of a specific relationship between the maintenance and stagnation of rural spaces.

KEY WORDS: field, field emptying, school education

\section{NEGACIÓN Y DESPOBLACIÓN DEL CAMPO: ¿QUE LA ESCUELA TIENE QUE VER CON ESO?}

RESUMEN: El presente trabajo tiene por objetivo traer para el debate cuestiones que involucran el campo, más específicamente, el vaciamiento y envejecimiento de la población (campesina) y la escuela. Sobre todo, en las últimas décadas, hay un campo que se vacía y envejece. ¿Por qué viene ocurriendo? ¿Y la educación/ escuela en ese proceso? El texto trae un debate teórico con autores que discuten el tema en la actualidad. La organización estructural del texto busca demostrar que el fenómeno estudiado está directamente relacionado a su contexto, lo que permite una reflexión más allá de las imposiciones del capital para la educación del campo. Las discusiones, análisis y conclusiones muestran que la condición de la reproducción de la agricultura campesina (más afectada por el fenómeno) es un hecho central en el establecimiento de una relación específica entre el mantenimiento y el estancamiento de los espacios rurales.

PALABRAS CLAVE: campo, vaciado del campo, educación escolar. 


\section{Introdução}

O projeto de modernização da nação brasileira trouxe uma necessidade de se "explicar" o campo, em contraposição à cidade. O mundo urbano passa a ser relacionado à própria modernidade, pois, é o centro das grandes inovações tecnológicas, e, ao campo, cabe o papel "secundário" de servir às grandes transformações, fornecendo matéria-prima e alimentando o grande contingente populacional urbano. A busca de explicações para os contrastes entre o mundo urbano e o mundo rural leva a uma identificação da cidade como o local do "progresso" e do campo como o local do "atraso". Essas criações estereotipadas levam à "invizibilização" da diversidade, ao mesmo tempo em que naturalizam as diferenças sociais, já que a visão de mundo da burguesia passa a se impor sobre a sociedade como a única legítima. E mais, a mesma passa a ser parte do processo de construção da nação, sendo que, de maneira geral, os indivíduos não entendem a filosofia burguesa como algo historicamente construído, mas, como pré-existente a eles - portanto, inatingível e indiscutivel.

Admitamos que, na maneira de conceber a marcha da história, se destacam as ideias da classe dominante dessa mesma classe dominante e que se consideram aquelas como uma entidade. Suponhamos que só nos interessa o fato de determinadas ideias dominarem numa certa época, sem nos preocuparmos com as condições de produção nem com os produtores dessas ideias, abstraindo, portanto, dos indivíduos e das circunstâncias mundiais que possam estar na base dessas ideias. Poder-se-á então dizer, por exemplo, que no tempo em que reinava a aristocracia, estava-se em pleno reinado dos conceitos de honra, de fidelidade, etc., e que no tempo em que reinava a burguesia existia o reinado dos conceitos de liberdade, de igualdade, etc. (MARX; ENGELS, 2002, p. 30).

Tal processo contribui para a neutralização das lutas e dos processos de conscientização dos sujeitos. O conceito mais adequado de consciência nesse caso seria aquele desenvolvido por Marx e Engels (2002) em A Ideologia Alemã, e discutido posteriormente por diversos estudiosos. Para o pensador não se trata de uma consciência pura, em si, mas, um processo de desenvolvimento da consciência que tem relação com o mundo material e prescinde deste. Por- 
tanto, apercebendo-se do mundo material, têm capacidade de apropriarem-se deste mundo para modificar/alterar a realidade conforme sê-lhes apresenta. Nas notas de rodapé da referida obra afirma que

Os homens têm uma história pelo fato de serem obrigados a produzir a sua vida e de terem de o fazer de um determinado modo: esta necessidade é uma consequência da sua organização física; o mesmo acontece com a sua consciência: apercebemo-nos de que, entre outras coisas, o homem tem "espirito", e que esse "espirito" se "manifesta" como consciência (MARX; ENGELS, 2002, p. 29).

Marx e Engels (2002) consideram a existência do objeto real fora da consciência, ou seja, opõe-se ao idealismo: para existir enquanto consciência, o objeto existe, tendo sido modificado ou não pelos sujeitos. O que vem antes da consciência caracteriza-se como "objeto em si". A partir deste, o que é produzido ou apropriado pelo sujeito caracteriza-se como "objeto para si", é algo que foi tomado "para si". É, sem dúvidas, um elemento novo na realidade, criado conscientemente a partir de algo anterior, o objeto em si. Em sua clássica obra sobre $O 18$ Brumário de Louis Bonaparte, Marx (2011) afirma que os homens produzem história, mas que não o fazem nas condições que desejam. Tal frase nos dá a dimensão histórica dos seres, das relações sociais e de sua essência.

Essa condição histórica do ser, essa historicidade imanente do ser que Marx e Engels enfatizam, dá a noção de um sujeito, ao mesmo tempo, reprodutor e produtor da realidade. A realidade concreta existe independentemente da consciência dos sujeitos particulares (a consciência "em si" da realidade) mas a ideia do "para si" representa, nesses termos, uma apropriação consciente a partir do que está posto (a consciência "para si" da realidade) (EUZÉBIOS FILHO, 2010, p. 36 e 37).

Portanto, segundo Duarte (1993), o indivíduo para si é o ser humano cuja individualidade está em permanente busca de relação consciente com o gênero humano. Ou seja, consciência para si seria o mesmo que a consciência de classe. Alemã

Marx e Engels (2002) assim sistematiza tal processo em A Ideologia 
Os pensamentos da classe dominante são também, em todas as épocas, os pensamentos dominantes, ou seja, a classe que tem o poder material dominante numa dada sociedade é também a potência dominante espiritual. A classe que dispõe dos meios de produção material dispõe igualmente dos meios de produção intelectual, de tal modo que o pensamento daqueles a quem são recusados os meios de produção intelectual está submetido igualmente à classe dominante. Os pensamentos dominantes são apenas a expressão ideal das relações materiais dominantes concebidas sob a forma de ideias e, portanto, a expressão das relações que fazem de uma classe a classe dominante; dizendo de outro modo, são as ideias do seu domínio. Os indivíduos que constituem a classe dominante possuem entre outras coisas uma consciência, e é em consequência disso que pensam; na medida em que dominam enquanto classe e determinam uma época histórica em toda a sua extensão, é lógico que esses indivíduos dominem em todos os sentidos, que tenham, entre outras, uma posição dominante como seres pensantes, como produtores de ideias, que regulamentem a produção e a distribuição dos pensamentos da sua época; as suas ideias são, portanto, as ideias dominantes da sua época (MARX; ENGELS, 2002, p. 29).

\section{Considerando a alienação ${ }^{3}$ enquanto fundamental para a burguesia impor sua visão de mundo sobre as demais classes sociais, e considerando que à burguesia interessa o esvaziamento do campo para sua total transformação em capital, afirmamos aqui que a manutenção das relações não capitalistas}

\footnotetext{
${ }^{3}$ No sistema sociometabólico do capital, o trabalho, categoria essencial que distingue os seres humanos dos demais animais, promove as mediações entre natureza-natureza, homem-natureza e homem-homem. As relações onde os seres humanos se reconhecem plenamente no fruto de seu trabalho, sem o intermédio do sociometabolismo do capital (mediações de primeira ordem) são interrompidas a apropriadas pelo capitalismo, dando origem às chamadas mediações de segunda ordem, privando os seres humanos da humanização que Ihes seria natural. As mediações de segunda ordem do capital, os meios alienados de produção, afastam os seres humanos de sua condição humana e do fruto de seu trabalho, que se torna uma relação alienada e estranhada. Segundo Marx, alienação é o processos pelo qual os homens são separados do fruto de seu trabalho. Assim, torna-se possível que, por meio da exploração da força de trabalho do proletariado, a burguesia imponha seu modo de produção sobre as demais classes sociais. Como resultado disso, o próprio sujeito torna-se alienado, ou seja, desprovido de sentido para a vida. Cabe ressaltar que a alienação, assim posta, é histórica, apresentando, portanto, os pressupostos para sua superação e transformação dos seres humanos e da sociedade.
} 
dentro do campo - conforme a definição de campesinato ${ }^{4}$ utilizada aqui - depende de um processo de luta e de transformação social, processo no qual a transformação/libertação da escola é fundamental.

\title{
Educação do campo, no campo, para o campo.
}

A relação entre a educação do campo e a sucessão familiar deve ser cada vez mais considerada ao se elaborar currículos para as escolas do campo, pois a expulsão dos jovens e o consequente "envelhecimento" de tais comunidades podem provocar um esvaziamento de diversas delas no curso de alguns anos. Discutimos sucessão familiar sob o prisma de uma educação libertadora, que permita aos alunos do campo o vislumbre de opções, de escolhas, que Ihes possibilite, inclusive, deixar o campo, se for o caso, mas, não por expulsão.

A questão sucessória pode ser analisada levando-se em conta a relação entre as aspirações comunitárias e os anseios individuais (do pai, do filho, da mãe). No passado, especialmente nas décadas de 1960 e 1970, a pressão para a continuidade da profissão de agricultor era muito forte, até porque, se pensarmos na dificuldade de acesso a profissões e projetos de vida alternativos de vida aos filhos de camponeses, compreenderemos que seus horizontes eram escassos e pouco acessíveis. Havia, assim, uma tendência natural que levava os filhos a continuarem os pais. Para Woormtan (apud ABRAMOVAY, 1998),

\begin{abstract}
[...] a ligação ao mundo comunitário, a incorporação dos valores próprios à continuidade da profissão paterna está também na raiz desta fusão entre os objetivos da unidade econômica e as aspirações de seus membros. Quando esta fusão desaparece é que surge a questão sucessória na agricultura (WOORTMAN, apud ABRAMOVAY,1998, p. 27).
\end{abstract}

O que o autor afirma é que, quando a vontade individual, os desejos

\footnotetext{
${ }^{4}$ Campesinato é o conjunto de famílias camponesas que vivem em um determinado território. 0 termo em si carrega uma complexidade, indo além do fato de que tais sujeitos vivem na e da terra, posto que os camponeses são uma contradição no sistema capitalista, devido à forma com a qual se relacionam com a terra, que em tudo se diferencia do modo de produção capitalista. Assim, "Camponesas são aquelas famílias que, tendo acesso à terra e aos recursos naturais que ela suporta, resolvem seus problemas reprodutivos - suas necessidades imediatas de consumo e o encaminhamento de projetos que permitam cumprir adequadamente um ciclo de vida da família - mediante a produção rural, desenvolvida de tal maneira que não se diferencia o universo dos que decidem sobre a alocação do trabalho dos que se apropriam do resultado dessa alocação." (CALDART; FRIGOTTO, 2012, p. 115)
} 
particulares sobrepõem-se nas decisões familiares, em detrimento dos anseios do grupo, há o perigo iminente de caminharem para a "dissolução do modelo de organização social do grupo" (apud ABRAMOVAY, 1998, p. 27).

O que caracteriza a agricultura familiar neste sentido é que o pleno exercício profissional por parte das novas gerações envolve, mais que o aprendizado de um ofício, a gestão de um patrimônio imobilizado em terras e em capital. Desenvolvido a partir do trabalho de toda a família (ao qual o jovem se incorpora desde criança) este patrimônio possui um duplo conteúdo social: por um lado ele é base material de um negócio mercantil e por outro é sobre ele que repousa não só a manutenção, mas a própria organização da vida familiar. É neste sentido que a agricultura familiar, mesmo nos países capitalistas centrais onde ela perdeu inteiramente seus traços camponeses, pode ser definida pela unidade ente o negócio e a família. (ABRAMOVAY,1998 p. 18) ${ }^{5}$.

O debate sobre a sucessão familiar é bastante relevante aqui, visto que a sobrevivência da comunidade em si depende da permanência dos jovens no local, possibilitando a preservação da terra de vida e de trabalho. Mas, neste ponto, cabe nos perguntarmos: a educação formal contribui para o desenvolvimento da autonomia dos sujeitos do campo? Sem dúvidas, a educação pode ser uma das bases para o desenvolvimento da autonomia dos sujeitos e do desenvolvimento social do campo. Porém, cabe ressaltar que o campesinato brasileiro ainda se constitui enquanto grupo que desenvolve relativa autonomia (ou busca desenvolvê-la) com relação ao sistema capitalista. Tal especificidade reside, essencialmente, na consciência de classe e na auto identificação enquanto pertencente a um grupo. Ainda assim, para seu pleno desenvolvimento (e aí reside sua inserção no sistema capitalista), os grupos pressionam os governos e a sociedade como um todo para a preservação e o desenvolvimento justo de seu modo de vida. A educação do campo, pen-

\footnotetext{
${ }^{5}$ A oficialização da expressão agricultura familiar teve como objetivo estabelecer critérios para o enquadramento legal dos produtores rurais com certas características que os classificavam como agricultores familiares. Isso para obtenção, por parte desses agricultores familiares, de benefícios governamentais, sendo indiferente o fato de esses agricultores estarem em situação de subordinação perante as empresas capitalistas ou se eram reprodutores da matriz de produção e tecnológica dominante. Já a expressão agricultura camponesa comporta, na sua concepção, a especificidade camponesa e a construção da sua autonomia relativa em relação aos capitais. Incorpora, portanto, um diferencial: a perspectiva maior de fortalecimento dos camponeses pela afirmação de seu modo de produzir e de viver, sem com isso negar uma modernidade que se quer camponesa. (CALDART; FRIGOTTO, 2012, p. 31)
}

Rev. Fac. Educ. (Univ. do Estado de Mato Grosso), Vol. 31, Ano 17, № 1, p. 135-159, jan./jun., 2019 
sada por seus sujeitos, torna-se e é importante instrumento de libertação e desenvolvimento social do campo.

A educação do campo vem sendo discutida por seus sujeitos, essencialmente camponeses e movimentos sociais populares ligados ao campo, e torna-se uma categoria conceitual, embora em constante reconstrução. Para além do espaço escolar formal, a educação do campo engloba seus sujeitos, suas práticas, suas vivências em comunidade. Assim, para Caldart; Frigotto (2012)

A Educação do Campo nomeia um fenômeno da realidade brasileira atual, protagonizado pelos trabalhadores do campo e suas organizações, que visa incidir sobre a política de educação desde os interesses sociais das comunidades camponesas. Objetivo e sujeitos a remetem às questões do trabalho, da cultura, do conhecimento e das lutas sociais dos camponeses e ao embate (de classe) entre projetos de campo e entre lógicas de agricultura que têm implicações no projeto de país e de sociedade e nas concepções de política pública, de educação e de formação humana. (p. 259)

Consideramos que é importante e indispensável a continuidade da formação profissional dos membros da comunidade para o desenvolvimento da mesma. Cabe aqui o texto de Harbinson (apud SPAGNOLO, 1972), com o qual concordamos plenamente, quando falamos de desenvolvimento social e autonomia dos sujeitos do campo:

Em nossa época, em que todos aspiram a posições mais elevadas e na qual as comunicações coletivas se estendem, os filhos dos agricultores não se condenarão certamente, se eles puderem evitá-lo, a passar suas vidas na agricultura tradicional. A única solução verdadeira é a modernização da vida rural. Dever-se-á, portanto, adotar medidas radicais como a reforma agrária, a pesquisa agrícola e a assistência técnica, vastos programas de desenvolvimento das comunidades rurais, utilização eficaz da mão-de-obra rural para a construção de estradas, de canais de irrigação, de casas e de escolas, e outros programas visando tornar a vida, ao mesmo tempo, mais produtiva e mais atraente. Se os habitantes das regiões rurais encontrassem razões de permanecer no campo, e se eles tiverem a promessa de uma vida melhor, o problema da revisão dos programas escolares será relativamente fácil de resolver (HARBINSON apud SPAGNOLO,1972. p. 19). 
Por outro lado, há uma confusão entre a formação dos camponeses e sua profissionalização. Isso porque em muitos currículos elaborados para as escolas do campo, "trabalho" confunde-se com subordinação ao capital. Assim, cada vez mais são criados cursos, voltados para a formação profissional do homem do campo, visando ensinar a este o trabalho no campo, com a justificativa de que os tempos são outros, e que o campo deve modernizar-se. Modernizar-se, neste caso, significa aproximar-se do urbano, significa produzir de maneira a satisfazer as demandas impostas pela cidade. Mais uma vez perde-se a possibilidade de emancipação dos sujeitos do campo pela via da educação. Os cursos de extensão rural, em geral, não visam a autonomia dos sujeitos do campo pela via da educação. Visam, antes, reproduzir as estruturas capitalistas de mercantilização e burocratização do trabalho no campo.

A busca pela autonomia dos sujeitos do campo é uma discussão cada vez mais urgente, visto que, apesar de todas as lutas travadas pelas organizações camponesas, ainda não são oferecidas condições para que os habitantes do campo possam realizar-se plenamente no campo. Afirmamos isso tentando não idealizar a vida no campo, nem tampouco a permanência dos camponeses no mundo rural. O processo de expulsão ocorre, em larga medida, quando o campo não oferece tais condições de vida e de desenvolvimento social. Além disso, o crescente processo de concentração e reorganização do capital leva à concentração de terras, pressionando e expulsando o pequeno trabalhador do campo.

O aspecto central que discutimos aqui é que a fetichização da educação pode levar o camponês a uma busca constante pela realização pessoal e do grupo através da conclusão dos estudos via educação. Mas, concomitante, a tal desejo, nasce o temor de que, ao terem contato com a vida na cidade, os filhos não retornem. E é, em grande parte, em torno dos debates relacionados à sucessão familiar no campo que podemos vislumbrar se tal espaço de luta poderá ser vitalizado, com um grupo de jovens envolvidos com sua valorização, ou se a tendência se confirmará, rumando para seu esvaziamento. Afinal, quem serão os responsáveis pelo meio rural daqui em diante? Apenas os grandes grupos financeiros, conforme nos apontam as tendências do mercado global?

Ao investigar o processo de sucessão no campo através da busca pela educação de qualidade nas cidades, evidenciamos o debate dentro da própria comunidade, buscando ali soluções para o problema podendo, sobre esta base, lutar por políticas públicas que reforcem a autonomia de tais sujeitos, ampliando as possibilidades de realização do jovem em sua comunidade. Entendendo educação como um direito inalienável de todo cidadão, compreende-se que 
esta constitui-se como ferramenta importante que possibilita ao jovem maior poder de escolha. Permite que possam ler melhor a realidade que os cerca, tomando decisões mais acertadas e conscientes. Que se tornem cidadãos mais participativos, cooperativos, enfim, que se tornem cidadãos. (PERIPOLLI,2011).

A relevância do desenvolvimento da educação do campo é um debate que está na pauta dos governos há bem menos tempo que os debates sobre educação de maneira geral. Suas especificidades foram ignoradas até bem recentemente. $O$ importante aqui não é apenas a garantia das discussões, mas a contextualização das diferenças e o protagonismo daqueles que lutam há anos pelo reconhecimento da necessidade de uma educação pensada para as populações do campo. Mesmo que os documentos dos organismos internacionais tratem o campo de maneira muito genérica, o tratamento diferenciado dado a tais populações significa já um grande avanço nas discussões das políticas públicas em tal área. Assim, unidos aos debates realizados pelos grupos de militantes dos países periféricos, acreditamos ser possível o vislumbre de mudanças no modelo de educação pensada para o campo, ainda hoje muito pautada nos modelos das escolas urbanas.

Em artigo recente sobre a educação do campo, Peripolli (2011) coloca assim a situação:

Há que se chamar a atenção também para o fato de que o cultivo dessa imagem negativa, estigmatizada do campo, tem resultado na prática, na oferta de políticas compensatórias, materializadas em uma educação de baixa qualidade, em decorrência da contratação de professores sem qualificação adequada ("leigos"), veiculada em estruturas físicas precárias (barracões), transporte (sucateado), métodos e conteúdos adaptados do meio urbano, distante das preocupações e necessidades dos alunos e da comunidade camponesa (PERIPOLLI, 2011. pp. 60 e 61).

Essa visão arcaica da educação para o campo está diretamente relacionada com a visão criada sobre o campo e o camponês. Contraditória essa visão, se pensarmos que o campo é das áreas que atualmente mais vem passando por progressos tecnológicos e científicos. Uma educação que respeite a autonomia de seus sujeitos e que possibilite sua sobrevivência enquanto grupo é urgente. Afinal, não é só a escola do campo que se esvazia, mas o campo como um todo. Quando o aluno deixa a escola do campo, a família, em geral, deixa o campo (ou, no mínimo, deixa de acreditar na revitalização da terra de 
vida e de trabalho).

Como, então, garantir uma educação de qualidade e comprometida com os anseios das populações do campo se as condições infraestruturais de tais escolas ainda são precárias? Pensar uma educação de qualidade para os jovens e adultos do campo é ir além da já tão conhecida promessa de se levar a qualidade da cidade para o campo. O que ocorre é que, de maneira geral, quando se pensa a estrutura física das escolas do campo, além de se copiar o modelo da cidade, leva-se "o resto" das escolas urbanas para o campo: ônibus inutilizados, livros didáticos que sobraram do ano letivo anterior e que foram substituídos, professores que não conseguiram aulas nas cidades e que vão para o campo por falta de opção, quadros negros antigos e que estavam há tempos encostados. Esta falta de recursos voltados e pensados para as escolas do campo, faz com que o campo seja sempre a sobra da cidade. E isso não só nas escolas, mas nas relações com o campo de maneira geral (BRITO,2015).

Concordamos com Machado (2009) quando esta afirma que o campo deve ser pensado para além do local físico em si, mas, enquanto categoria de organização social e política de trabalhadores que lutam pela terra e vivem dela. Afinal, os sujeitos da educação do campo são os sujeitos da resistência no e do campo.

\section{As escolas do campo e a legislação brasileira}

Pensar a organização escolar (no campo ou na cidade), na perspectiva de uma educação libertadora, "para além do Capital", passa pela construção de currículos coerentes com os anseios dos sujeitos e grupos em construção, em relação com os outros grupos. Passa pela reflexão sobre qual o papel do campo na sociedade atual, entendido aqui como, muito mais que um espaço físico, de fronteira, um espaço de sujeitos ativos, coerentes, um espaço familiar, onde vivem pessoas que optaram por ali viverem e se desenvolverem plenamente. Mas, então, porque os currículos escolares do campo, em geral (mesmo com todos os debates feitos pelos diversos atores da educação do campo) ainda não passam de meras cópias mal acabadas dos currículos das escolas urbanas? Uma conclusão bastante evidente, aqui, é a de que ao capital não interessa o desenvolvimento autônomo dos sujeitos do campo a não ser para que estes sirvam ao capital. Os currículos escolares cuidam para que seja inculcada no imaginário dos camponeses, desde a infância, a ideia de que a felicidade se encontra nos centros urbanos. Que os que vivem no campo estão ali apenas

Rev. Fac. Educ. (Univ. do Estado de Mato Grosso), Vol. 31, Ano 17, № 1, p. 135-159, jan./jun., 2019 
por falta de opção, ou seja, os que ficaram no campo são aqueles derrotados profissionalmente. A valorização dos saberes camponeses e da vida no campo quase nunca está presente, na prática, nos currículos escolares do campo ou da cidade.

A garantia legal da educação pública, gratuita e de qualidade para todos, sem discriminação, está presente na Constituição Brasileira, quando nos coloca a todos como iguais perante a lei. Além disso, está no projeto da nação a presença do Estado enquanto tutelador e garantidor dos direitos dos cidadãos, inclusive, e principalmente, aos direitos aos estudos, sejam estes nos centros urbanos ou no campo, sejam estes cidadãos brancos, negros, homens, mulheres, crianças, enfim, sem distinção de qualquer natureza.

Está claro que o texto da Constituição Brasileira trata apenas de maneira geral o acesso aos direitos essenciais dos cidadãos brasileiros. Os anos 90 foram decisivos para a mudança nas concepções sobre educação e, no caso que nos interessa aqui, em educação do campo. Juntamente com a guinada de governos neoliberais, cria-se a ideia de educação enquanto fetiche, enquanto a única e mais nobre maneira de se libertar os cidadãos brasileiros da ignorância e adentrar o admirável mundo novo, onde a modernidade não mais está relacionada ao chão da fábrica, mas, a cidadãos autônomos, que não dependem mais da tutela total do Estado. O novo Brasil, mascarado pelo capuz do neoliberalismo, escondia não só a real cara do governo, mas também as desigualdades sociais cada vez mais gritantes e a total submissão do país ao capital internacional. Nessa perspectiva de transnacionalização do capital, o BVM (Banco Mundial) e o FMI (Fundo Monetário Mundial) adentram na ideologia dos currículos escolares brasileiros, num claro anseio pela velha e boa fórmula que soma formação rápida e superficial, mão de obra barata e privatização da educação. É nessa lógica que é escrita a Lei de Diretrizes e Bases da Educação Nacional. Foi somente a partir da LDB (Lei de Diretrizes e Bases da Educação Nacional - 9394/96), que a Educação do Campo foi tratada de maneira específica, não apenas enquanto extensão do direito de todo e qualquer cidadão, mas enquanto conceito e direito de populações específicas. O Artigo 28 da LDB diz que

Na oferta de educação básica para a população rural, os sistemas de ensino promoverão as adaptações necessárias à sua adequação às peculiaridades da vida rural e de cada região, especialmente: I - conteúdos curriculares e metodologias apropriadas às reais necessidades e interesses dos alunos da zona rural; II 
- organização escolar própria, incluindo adequação do calendário escolar às fases do ciclo agrícola e às condições climáticas; III adequação à natureza do trabalho na zona rural (BRASIL,1996).

No referido documento, a Educação do Campo é tratada ainda enquanto adaptação da educação urbana. Não se esperaria algo diferente na conjuntura brasileira do período onde, somada à internacionalização da educação e a privatização do ensino público, houve um significativo fenômeno de enfraquecimento dos movimentos sociais, característica marcante dos governos neoliberais que mascaram os problemas estruturais. Note-se que a Educação do Campo está ligada diretamente à autonomia dos sujeitos do campo. A construção de uma escola de qualidade depende diretamente da luta dos camponeses pela educação de qualidade. Por outro lado, considera as diferenças e peculiaridades das populações do campo, quando estabelece que as metodologias e os conteúdos curriculares devam ser adaptados às reais necessidades de cada localidade, considerando ainda suas peculiaridades, como condições climáticas regionais e calendários festivos locais.

Mas, tal processo pode resultar em uma fragmentação do conjunto das populações rurais, já que as mesmas adquirem relativa autonomia de existência com relação às demais. É o que nos aponta Peripolli (2009):

Diante de universos regionais tão ricos em diversidades sócio-culturais, climáticas, econômicas, etc., porém, fazendo parte de um todo comprometido com as leis que regem a sociedade capitalista, há que se perguntar se é possível pensarmos em realidades regionais ou mesmo locais? Ou seja, seria/é possível separá-las do todo e vivenciar suas singularidades? Nesta tentativa, não estaríamos falando de algo artificial, uma vez que nada escapa à totalidade do processo que o capitalismo engloba? (p.103).

O autor prossegue a discussão:

Paulo Freire (2005, p. 162) nos chama a atenção a este respeito ao dizer que 'estas formas focalizadas de ação, intensificando o modo focalista de existência das massas oprimidas, sobretudo rurais, dificultam sua percepção crítica da realidade e as mantêm ilhadas da problemática dos homens oprimidos de outras áreas em relação dialética com a sua. (PERIPOLLI, 2009, p. 104). 
Não é necessário dizer que não pretendemos desconsiderar as políticas públicas que agem no sentido de considerarem as populações do campo e suas especificidades. Apenas achamos conveniente lembrarmos que, em se tratando de um legislativo que, em geral, privilegia as classes dominantes, não devemos apreciá-la de forma passiva, nem acreditar que a mesma vem como um presente às populações do campo. A legislação, via de regra, não visa favorecer os oprimidos em detrimento dos opressores, senão por meio de luta por parte do povo.

A luta de classes está sempre presente nas mudanças sociais que ocorrem em todos os períodos da história do Brasil, diferente do que apregoam os intelectuais da pós-modernidade, que afirmam veementemente o fim da história e da luta de classes. Graças à articulação dos movimentos sociais e de sujeitos do campo cada vez mais conscientes de sua condição enquanto grupo, novos documentos são publicados, com o intuito de definir-se a identidade das escolas do campo. Assim, a articulação dos movimentos sociais, dos trabalhadores do campo, especialmente do MST (Movimento dos Trabalhadores Rurais Sem Terra) vão discutindo novos rumos para a educação do campo.

Mas, para Saviani (1998), a LDB foi constituída de maneira a privilegiar o mundo urbano sobre o rural, sendo a educação uma espécie de passaporte para a vida urbana, onde tais populações teriam acesso ao trabalho e à liberdade (no sentido capitalista do termo). Sendo assim, a escola do campo foi projetada para ter como modelo as escolas urbanas. E o que é pior: a LDB, nas palavras de Saviani, seria uma lei "autoritária", que acaba por silenciar vozes discordantes, já que se propõe como matriz da organização legal da educação do país.

Significativa é a publicação, em 2002, pela Câmara de Educação Básica, do Conselho Nacional de Educação, das Diretrizes Operacionais para a Educação Básica nas Escolas do Campo. Nestas Diretrizes a identidade da Escola do Campo é definida, no Art. 2ํ, Parágrafo único

[...] pela sua vinculação às questões inerentes à sua realidade, ancorando-se na temporalidade e saberes próprios dos estudantes, na memória coletiva que sinaliza futuros, na rede de ciência e tecnologia disponível na sociedade e nos movimentos sociais em defesa de projetos que associem as soluções exigidas por essas questões à qualidade social da vida coletiva no país (BRASIL,2002).

A publicação das Diretrizes representa, assim, grande avanço com 
relação aos direitos dos povos do campo. Os sujeitos do campo passam a ser tratados enquanto seres autônomos, com especificidades. Principia-se, no tratamento dado à educação do campo, uma visão, proposta pelos movimentos de trabalhadores e trabalhadoras do campo, de revitalização do espaço do campo enquanto terra de vivências e reflexões. Aqui, como nos lembra Peripolli (2009), fala-se em um processo de ruptura, pois, à classe que detém o grande poder econômico interessa transformar o campo em espaço para o agronegócio.

A Educação do Campo buscada pelos sujeitos do campo por meio dos movimentos populares passa a vincular-se à própria definição/sedimentação da identidade do homem do campo, numa visão cada vez mais distante do "Jeca Tatu", daquele que fica na "roça" por falta de opção, mas, de homens e mulheres que se enxergam enquanto parte do projeto de nação, com projeto próprio de educação, de sujeitos em construção, de uma escola e de um campo ativos, dinâmicos, e, por que não, modernos, tecnológicos, em consonância com as facilidades e vantagens do mundo moderno. Mas, se a educação do campo presente nos documentos oficiais aproxima-se cada vez mais do projeto definido pelos movimentos populares do campo, a prática da Educação do Campo afasta-se mais e mais dele. É no chão da escola que encontramos as maiores dificuldades e problemas a serem enfrentados pelo campo brasileiro. Há uma enorme e muito conhecida distância entre a lei e a realidade. Talvez isso se deva ao fato de que, apesar dos esforços dos movimentos de luta pela revitalização do campo, a educação (no campo e na cidade) ainda constitui-se num mero reprodutório de mão de obra barata e mal qualificada para o mercado de trabalho. O projeto de campo para o Brasil não prevê outro lugar para o camponês senão as periferias das grandes, médias e até mesmo das pequenas cidades. "A aprovação das Diretrizes, ao mesmo tempo em que representa um ponto de chegada, quer significar também um ponto de partida, pois as mudanças se fazem no movimento e as conquistas só se consolidam com muita persistência" (PERIPOLLI,2009, p. 117).

Como, então, revitalizar o espaço do campo por meio da educação, se o projeto de nação brasileira relega ao campo a ingrata missão de fornecedora de matéria-prima para alimentar o capital internacional? Qual o espaço reservado ao camponês e à agricultura camponesa no admirável mundo novo?

A terra, com todos os seus significados - solos, águas, florestas, campos, desertos, savanas, fauna, flora e cultura dos povos que dela e nela vivem é o núcleo da discussão sobre educação rural/

Rev. Fac. Educ. (Univ. do Estado de Mato Grosso), Vol. 31, Ano 17, № 1, p. 135-159, jan./jun., 2019 
do campo. Ela é meio essencial de sobrevivência do humano agricultor ou camponês, na sua tridimensionalidade, porque natureza, indivíduo e sociedade (...) Se, ao contrário, a terra é propriedade privada e reserva de capital, que não pertence a uma comunidade, mas a um indivíduo, sendo transmitida por herança, como garantir que os trabalhadores que não a possuem possam realizar-se como trabalhadores da/na terra? Como propor uma educação rural/do campo para jovens cujos pais não têm terra ou mesmo dispõem apenas de uma pequena parcela? (RIBEIRO, 2013, p.197).

Parece-nos que, a cada dia que passa, pais e mães de filhos do campo formarão seus filhos para, apropriando-se precariamente dos saberes técnicos, empregarem-se em grandes fazendas que vão engolindo as pequenas propriedades mais e mais. Exemplo claro disso são as escolas técnicas presentes no Mato Grosso: a oferta de cursos agro técnicos atraem os filhos de pequenos produtores, que, futuramente, serão empregados pelos latifúndios da região. Os currículos de tais escolas nos demonstram, mesmo em uma leitura superficial, a predominância da técnica para a agroexportação e monocultura.

\section{A “Crise dos paradigmas da História” e a negação do mundo rural}

O que define o rural e o urbano no Brasil de hoje? Que fronteiras se apresentam diante de uma sociedade sem fronteiras? Que divisões podemos expressar para definirmos o mundo urbano e o mundo rural? Definições bastante simplificadas foram aceitas há até bem pouco tempo atrás, e a legislação brasileira vigente demonstra essa problemática. O Decreto-lei 311 de 1938, ainda vigente, define como rurais as áreas que se encontram fora dos espaços delimitados pelas fronteiras urbanas, ou as áreas fora dos perímetros urbanos. O Decreto-Lei criado ainda pelo então presidente Getúlio Vargas, define como urbanas todas as sedes de municípios (cidade) e de distrito (vila), sendo estas áreas definidas por seus respectivos perímetros urbanos, que são justamente as linhas que separam o urbano do rural. Ocorre que a definição do perímetro urbano sempre esteve (e ainda está) cercada por interesses diversos (políticos, econômicos ou tributários). Não estamos a propor aqui uma nova definição do que seja o urbano e o rural no Brasil, mas, propomos que os dados oficiais sejam vistos com bastante cautela, pois, podem não refletir exatamente a realidade brasileira. 
As dinâmicas populacionais, econômicas, políticas e culturais, não nos permitem uma definição tão simplificada com relação aos espaços e fronteiras brasileiros. Acredito que uma análise cuidadosa leva em conta que há outros fatores relevantes nesse sentido. Ideologicamente e historicamente, há uma negação do espaço rural. Em princípio, com o advento da sociedade industrial nos séculos XVIII e XIX na Europa, a nobreza feudal, que perdera seu poder político-econômico para ascendente burguesia, agarrara-se ao mundo rural como se este fora seu único e último refúgio. Há aqui uma clara dicotomia entre o rural e o urbano: nas cidades, a revolução das máquinas e todos os benefícios que estas traziam consigo. No campo, a decadente nobreza com seu ranço feudal, buscando um retorno ao domínio do rural sobre o urbano, que representa seu próprio domínio sobre a sociedade. De um período em que a posse da terra representava poder e status, a Europa passa a uma revolução urbana, relacionada com o comércio e a industrialização. Muito além do plano econômico, tal dicotomia apresenta-se no plano ideológico, onde o rural passa a associar-se ao atraso e o urbano à modernidade. Ocorre, ainda, neste processo, uma dicotomia urbano-rural, onde os dois são as pontas opostas de uma reta.

Mas definir as dinâmicas de uma sociedade em uma reta não expressa toda a sua complexidade. Campo e cidade se mesclam, não se opõem. Nessa perspectiva, novas abordagens do espaço geopolítico brasileiro vão surgindo, onde o rural e o urbano apresentam-se num continuum. O problema, é que, ao quebrar a dicotomia urbano-rural, há uma invizibilização do mundo rural. Uma negação, a sobreposição do urbano sobre o rural. Ao afirmarmos que o campo e a cidade se complementam, reafirmamos aqui o campo enquanto local autônomo, não assumindo o papel de fornecedor de matérias-primas para a industrialização urbana. O campo também se industrializa, e é espaço fundamental de vivências e de sobrevivência de diferentes povos autônomos, e acreditamos que apenas a afirmação do espaço rural e a sua caracterização pelas lutas dos povos que com ele se relacionam e que dele retiram seu sustento dará a ele seu real sentido. Assim,

A separação entre o que é rural e urbano no Brasil, a exemplo do que já aconteceu com os países desenvolvidos, também passa a se tornar cada vez mais desnecessária diante de uma realidade cada vez mais complexa, que demonstra que estes conceitos se interpenetram mais a cada dia. De fato, é impossível realizar um recorte espacial perfeito diante de toda a complexidade de uma realidade composta por diferentes níveis de integração e 
distanciamento entre os espaços rurais e urbanos. Mas para fins de planejamento e formulação de políticas de desenvolvimento rural e urbano, torna-se coerente a realização de algumas subdivisões que não buscarão, necessariamente, a total superação entre as insuficiências teóricas e empíricas do que seja rural e urbano no Brasil, constituindo-se em uma alternativa que possui sua viabilidade justificada por razões de ordem prática. O que parece claro é que, nesse sentido, um recorte espacial em apenas duas categorias não responde de forma adequada os objetivos propostos, sendo necessária a criação de mais categorias para a realização de uma melhor captação das singularidades sócio espaciais" (BISPO; MENDES,2010, p.12).

Atualmente, diferentes dinâmicas espaciais apresentam-se dentro dos referidos espaços, pois, "o campo não é mais um espaço predominantemente rural. De forma semelhante, a cidade não é um espaço exclusivamente urbano, ou seja, nem tudo o que existe no campo é rural e nem tudo o que há na cidade é urbano" (BISPO; MENDES, 2010 p. 1).

O problema encontrado aqui é que, concomitantemente a essa relação do continuum rural-urbano, surge uma negação do mundo rural. Sua descaracterização, ou a vulgarização, que, acreditamos, relaciona-se com a crise dos paradigmas nas ciências sociais, chamada por alguns de paradigma pós-moderno ou sociedade do conhecimento. A negação da luta de classes enfraquece a classe trabalhadora, e é parte do projeto de desarticulação de classes imposta pelo capitalismo.

A quem pode interessar essa dissolução do mundo rural na sociedade atual? Essa descrença na revitalização do campo para os camponeses, e a aclamada modernização do espaço rural que exclui dela seus sujeitos, a quem beneficia? A modernização do campo para os camponeses afasta-se cada vez mais da realidade brasileira, onde o agronegócio adentra o espaço rural, munido do discurso de que campo e cidade modernizam-se para todos os brasileiros. Marlene Ribeiro faz uma bela reflexão a esse respeito, nos levando a pensar sobre aquele que, para muitos, seria o "destino" dos jovens do meio rural:

Algumas pessoas argumentam que a maioria dos jovens que vivem nas áreas rurais não está interessada em retornar ao duro trabalho com a terra. Mas seria destino ou imposição do capital, enquanto uma relação social apropriadora do trabalho, da terra e da ciência, que os inventos, no caso, os destinados a dinamizar a produção agrícola, a reduzir e a facilitar o trabalho do agricultor 
estejam associados às grandes propriedades? Seria o destino dos trabalhadores ou imposição do capital que não sejam criadas condições econômicas, sociais e culturais, junto com a posse da terra, que estimule os jovens a dar continuidade ao trabalho de seus pais? Seria destino dos jovens e adultos trabalhadores ou imposição do capital, enquanto uma relação social, que haja um contingente cada vez maior de jovens e adultos trabalhadores, nas periferias urbanas, que não encontram empregos amparados pela legislação trabalhista? (RIBEIRO, 2013, p. 197-8).

A entrada maciça de maquinário de alta tecnologia atinge os camponeses, mas ainda de modo bastante negativo. Falamos de modo geral. Assim como nos centros urbanos, a população pobre não tem acesso à industrialização tecnológica, acaba tornando-se escrava da tecnologia, adentrando na modernidade "pela porta dos fundos". Em grande medida, é o excedente de mão de obra. Com sorte, se tornará o operador das máquinas, e não seu dono.

Este é um discurso presente em documentos oficiais das políticas públicas educacionais para o campo. O Guia PNLD Campo (Programa Nacional do Livro Didático para as escolas do campo) - 2013 carrega tal discurso, quando afirma a necessidade do reconhecimento da identidade dos sujeitos do campo para o desenvolvimento de uma educação de qualidade para o campo. Contraditória tal visão, se pensarmos que é o próprio governo burguês quem privilegia o agronegócio em detrimento às populações camponesas. Vejamos um trecho do referido documento:

Destaca-se como um dos aspectos relevantes para o funcionamento de uma escola que possa ser considerada "do campo" o reconhecimento e a valorização da identidade de seus sujeitos. Reconhecer e valorizar implica construir e desencadear processos educativos, dentro, ao redor e no entorno da escola que não destruam a autoestima dos sujeitos pelo simples fato de serem do meio rural; de serem sem terra; de serem filhos de assentados; filhos de agricultores familiares; extrativistas; ribeirinhos; quebradeiras de coco, enfim, filhos de sujeitos camponeses cuja reprodução social se dá prioritariamente a partir dos trabalhos no território campesino (BRASIL, 2013, p. 11-2)

Apropriando-se do discurso popular, o que o governo faz é apresentar uma reforma curricular para as escolas do campo, buscando retirar dos textos oficiais algo que relacione a educação proposta pelo MEC (Ministério da Edu- 
cação e Cultura) a já superada fase do ensino tradicional. Com foco essencial no aluno e no respeito à diversidade, tal movimento reformista é bastante prejudicial à educação como um todo, já que, para usar a expressão de Mészáros (2008), o Capital é irreformável. 'Irreformável' porque, em hipótese alguma, a estrutura fundamental do capitalismo será alterada se reformada de dentro dele mesmo, especialmente se proposta pela burguesia, representada pela mão do Estado. Por isso,

Os princípios orientadores da educação formal devem ser desatados do seu tegumento da lógica do capital, de imposição de conformidade, e em vez disso mover-se em direção a um intercâmbio ativo e efetivo com práticas educacionais mais abrangentes. Eles (os princípios) precisam muito um do outro. Sem um progressivo e consciente intercâmbio com processos de educação abrangentes como a nossa própria vida, a educação formal não pode realizar as necessárias aspirações emancipadoras. (MÉSZAROS, 2008, p. 58-59, grifo do autor).

Acreditamos que apenas pela via revolucionária, pela emancipação dos trabalhadores e trabalhadoras, serão efetivadas as mudanças fundamentais na sociedade atual, e esta não será realizada pela burguesia, a quem menos interessa tal processo.

\section{Considerações finais}

Em geral, a população do campo no Brasil foi e é levada, ainda, a acreditar (pelas várias violências impostas ao longo de sua existência, desde a expulsão da terra natal até a atualidade, com a negação de direitos fundamentais) que seu modo de vida e organização no campo não valem a pena, e que sua existência no campo é apenas ocasionada pela falta de oportunidades de viverem nos centros urbanos. Podemos, assim, relacionar a negação do campo à opressão que tais populações trazem em si.

Parte do processo de mudança poderia estar presente na construção de currículos e na própria organização escolar das escolas do campo. Daí a relevância da construção de uma escola que não esteja meramente vinculada à formação voltada para o mercado de trabalho, mas, que auxilie na tomada de consciência e no reconhecimento de pertencimento a um grupo. Alguns princípios pedagógicos são fundamentais nesse processo: o trabalho coletivo e a gestão democrática, por exemplo. "A escola do campo tem uma função social 
que não pode ser desempenhada apenas pelo diretor ou pelos educadores, exigindo completa intersecção entre escola e assentamento ou comunidade" (MACHADO,2008, p.194). Apoderar-se da escola pode ser um longo processo, mas, que deve ser visto enquanto fundamental à construção da escola do campo que seja autônoma e permita à comunidade o vislumbre de novas possibilidades que não o abandono - por expulsão - do campo. Outros dois conceitos são fundamentais: Autonomia escolar e auto-organização do coletivo docente e infantojuvenil:

Na defesa de sua autonomia, cabe o entendimento de que a escola pode discutir e definir sua forma de funcionamento a partir do que sua realidade e seus princípios determinam, mesmo observando-se as diretrizes nacionais da educação. A compreensão de que o exercício da autonomia é essencial para a preservação de identidades e valores, estende-se aos educadores, às crianças e jovens, que procurarão se organizar em torno de interesses comuns, dimensionados pelos objetivos gerais da escola (MACHADO,2008, p. 194).

Assim, trabalho coletivo/gestão democrática, autonomia escolar/ auto-organização do coletivo escolar, podem se traduzir, na prática escolar, no espaço curricular, efetivando os princípios da construção de uma escola que pertença à comunidade. Currículo não é apenas uma relação de conteúdos a serem trabalhados de acordo com a série ou idade dos alunos (como muitas vezes ocorre na prática); tampouco é um documento que deve ficar arquivado na escola, para cumprir formalidades.

Currículo é expressão da cultura escolar e as práticas de ensino são usos nos quais essa cultura adquire sentido. É o currículo como práxis, em que as proposições teóricas e finalidades educativas se desdobram em um conjunto de atividades e de tarefas acadêmicas, executadas por educandos e educadores (MACHADO,2008, p. 195).

Tal conceito se apresenta para nós como fundamental para a construção da consciência sobre o ser camponês, imposta por diferentes formas. Nos documentos orientativos que baseiam a construção da educação do campo no Brasil, temos uma definição que pode nos dar pistas sobre o projeto de escola e o projeto de campo e camponês que se deseja construir para tal população específica. Tratando os moradores do campo de maneira uniforme, 
as especificidades acabam sendo deixadas de lado, criando-se um camponês "genérico", sem individualidades. As discussões feitas pelos movimentos em prol da educação do campo são essenciais, mas o envolvimento da comunidade para a produção de uma educação que atenda às reais necessidades da comunidade é fundamental.

Seria essa a reflexão feita por Ribeiro (2013), referenciando Arroyo, que traz uma discussão bastante profunda, fruto de anos de diálogos com movimentos populares. Para a autora, podemos sintetizar em três as questões sobre a educação do campo:

Como vemos os sujeitos de direitos à educação do campo: como indivíduos ou como coletivos ou, ainda, como pessoas e, ao mesmo tempo, coletividades? E, a partir desta: Como vemos a educação do campo: como uma abstração generalizante, aplicada a todos, sem contemplar a ninguém em particular, ou como formação humana dentro de um contexto histórico-social concreto? A quem cabe fazer/oferecer essa educação que não está pronta nem definida pelos manuais? (RIBEIRO, 2013, p. 184-5).

Estamos ainda distantes de uma educação do campo que contemple os anseios das populações a que se destinam, embora esteja nas pautas dos movimentos populares a construção dessa educação. Os anos de história de uma educação pensada de fora (muitas vezes pelo capital internacional, que busca se apropriar cada vez mais do campo brasileiro, expulsando dele o camponês), não deixam de fazer parte da constituição dessa escola, estando ainda muito presentes. A desestruturação do modo de vida dos camponeses passa, sem dúvidas, pela desestruturação das escolas.

A visão "moderna" da cidade em contraposição ao "arcaico" do campo tem justificado a adoção de políticas seja para "superar" o atraso do camponês, como vários autores têm mostrado, mas também para diminuir os custos com a educação da população rural, cujo destino, nessa compreensão, é o deslocamento para os centros urbanos. Nesse sentido, as políticas de nucleação de escolas e de transporte das crianças e adolescentes do campo para as escolas das cidades radicalizaram essa prática e esse paradigma urbano (RIBEIRO, 2013, p. 184). 
Neste momento, em que as forças antagônicas presentes na sociedade acirram mais e mais suas contradições, o campesinato apresenta-se enquanto força de oposição, de luta pela manutenção de seu modelo de organização e de resistência à absorção completa pelo modelo dominante de produção, de relação com a terra, de organização familiar, etc.

\section{Referências}

ABRAMOVAY, Ricardo. Juventude e agricultura familiar: desafios dos novos padrões sucessórios. Brasília: Unesco, 1998.

BISPO, Cláudia Luiz de Souza; MENDES, Estevane de Paula Pontes. O rural e o urbano brasileiro: definições em debate. Anais do XVI Encontro Nacional dos Geógrafos. Porto Alegre/RS, 2010.

BRASIL, MEC. Diretrizes Operacionais para a Educação Básica nas Escolas do Campo. Resolução nํ 1, de 03 de abril de 2002.

Lei de Diretrizes e Bases. Lei no 9.394/96, de 20 de dezembro de 1996.

MEC. Guia de livros didáticos: PNLD Campo 2013: Guia de Livros. Brasília: Ministério da Educação, Secretaria de Educação Continuada, Alfabetização, Diversidade e Inclusão, 2012.

. Decreto-lei 311, de 02/03/1938. http://www.planalto.gov.br/ccivil_03/decreto-lei/1937-1946/Del0311.htm Acesso em 08/05/2019.

BRITO, Flávia Lorena. O Esvaziamento do Campo e da Escola Entre os Jovens Camponeses: O Caso da Comunidade da Voadeira - Barra do Garças/MT. Dissertação (Mestrado). PPGEDu/Unemat. 167 p. Cáceres-MT, 2015.

CALDART, Roseli Salete; FRIGOTTO, Gaudêncio (org.). Dicionário de Educação do Campo. Rio de Janeiro/São Paulo: Expressão Popular, 2012.

CAMARANO, Amélia; ABRAMOVAY, Ricardo. Êxodo rural, envelhecimento e masculinização no Brasil: panorama dos últimos cinquenta anos. In: ENCONTRO ANUAL DA ANPOCS, 21, 1998, Caxambu, MG Anais... Caxambu: ANPOCS, 1998.

DUARTE, Newton. As pedagogias do "aprender a aprender" e algumas ilusões 
da assim chamada sociedade do conhecimento. Revista Brasileira de Educação. Set./Out./ Nov./Dez 2001, no 18. Disponível em: http://www.scielo.br/ pdf/rbedu/n18/n18a04.pdf. Acesso em: 22/04/2014.

EUZÉBIOS FILHO, Antônio. Sujeito e Consciência: entre a alienação e a emancipação. Tese (Doutorado) PUC-Campinas, 2010.

FREITAS, Luis Carlos. Crítica da Organização do Trabalho Pedagógico e da Didática. Campinas: Papirus, 1995.

MACHADO, Ilma Ferreira. Qual a Organização Curricular Necessária à Escola do Campo? In: CARVALHO, Diana Carvalho de et al. (org). Currículo, diversidade e formação. Florianópolis, Ed. Da UFSC, 2008.

; VENDRAMINI, Célia Regina. Políticas públicas para a educação do campo: da necessidade aos limites. Disponível em: seer.fclar.unesp.br/iberoamericana/article/viewFile/6470/4779 (Acesso em 13/01/2015, às 18h00min)

MARX, Karl; ENGELS, Friedrich. A Ideologia Alemã, 10 Capítulo: seguido das teses sobre Feuerbach (trad.: Silvio Donizete Chagas) São Paulo: Centauro, 2002.

MÉSZÁROS, István. A educação para além do capital. 2ª ed. São Paulo, Boitempo: 2008.

PERIPOLLI, Odimar João. Expansão do Capitalismo na Amazônia Norte mato-grossense: a mercantilização da terra e da escola. Tese (Doutorado). FAED/ UFRGS.276p. Porto Alegre/RS, 2009.

. O processo de esvaziamento do campo entre os jovens camponeses: os desafios colocados à escola. Revista da Faculdade de Educação/Universidade do Estado de Mato Grosso: Multitemática. Ano IX, no 16 (jul./dez. 2011) Cáceres: Unemat Editora.

REIS, Douglas Sathler dos, O Rural e Urbano no Brasil. Trabalho apresentado no XV Encontro Nacional de Estudos Populacionais, ABEP, realizado em Caxambú- MG - Brasil, de 18 a 22 de setembro de 2006.

RIBEIRO, Marlene. Movimento Camponês, trabalho e educação: liberdade, autonomia, emancipação: princípios/fins da formação humana. 2. ed. São Paulo: Expressão Popular, 2013. 
SAVIANI, Demerval. Da nova LDB ao Novo Plano Nacional de Educação: por uma outra política educacional. São Paulo: Autores Associados, 1998.

SPAGNOLO, Fernando. Escola e educação para o trabalho no meio rural: O caso de Barra do Corda. São Paulo, CENAFOR, 1972.

VIANA, Nildo. A Dialética como Ideologia. Fragmentos de Cultura, Ifiteg/UCG. Vol 12, Especial, Março/2011, pp. 95-116.

Data de recebimento: 08.05.2019

Data de aceite: 07.06.2019 